\title{
Transformações no mundo do trabalho: o perfil do emprego doméstico nos anos 90 e 2000
}

\author{
Juliane da Costa Furno ${ }^{l}$
}

Natasha da Silva Pergher ${ }^{2}$

Resumo: Este trabalho procura fazer uma análise da situação do trabalho doméstico no Brasil entre as décadas de 90 e os anos 2000. Esse recorte temporal busca problematizar as transformações no mundo do trabalho a partir das experiências de cunho neoliberal - identificados nos anos 90 sob a governança de Fernando Henrique Cardoso - e as transformações cunhadas nos anos 2000, sob uma perspectiva "neodesenvolvimentista", representada pela figura do ex-presidente Lula. No artigo procuramos refletir de forma mais geral sob as diferenças e desigualdades relacionadas ao gênero no mercado de trabalho, problematizando a divisão sexual do trabalho e as questões subjetivas relacionadas com a condição de mulher e trabalhadora. Como recorte de análise procuramos analisar, a luz dessas categorias, o mercado de trabalho doméstico, composto - majoritariamente por mulheres- e que reflete algumas características do papel destinado à mulher na sociedade, bem como aspectos da formação econômica e social da sociedade brasileira.

\footnotetext{
${ }^{1}$ Graduada em Ciências Sociais Universidade Federal do Rio Grande do Sul. Faz mestrado em desenvolvimento econômico pela Universidade Estadual de Campinas. Área de concentração: economia social e do trabalho.

${ }^{2}$ Graduada em Ciências Econômicas pela Pontifícia Universidade Católica do Rio grande do Sul, é mestranda em Ciências Econômicas pela Pontifícia Universidade Católica do Rio Grande do Sul, na área de desenvolvimento econômico.
} 
Palavras-chave: Gênero; Mercado de Trabalho; Trabalho doméstico; Sindicatos.

Abstract: This paper attempts to analyze the situation of domestic work in Brazil between the decades of the 2000s and 90 This time frame raises questions on transformations in the world of work from the experiences of neoliberal -. Identified in the 90s under the governance of Fernando Henrique Cardoso - and minted transformations in the 2000s, under a "neodesenvolvimentista" perspective, represented by the figure of former President Lula. In the paper we reflect more generally on gender differences and inequalities related to gender in the labor market, questioning the sexual division of labor and subjective issues related to being a woman and working. As cut analysis we analyzed the light of these categories, the market for domestic work, compound mostly women and reflecting some characteristics of the role assigned to women in society, as well as aspects of economic and social development of Brazilian society.

Keywords: gender; Labour Market; Domestic work; unions

\section{Introdução}

A regulamentação do mercado de trabalho no Brasil inicia com o governo de Getúlio Vargas, no bojo do processo de industrialização da economia brasileira. Inicialmente, as leis trabalhistas restringiam-se aos trabalhadores urbanos, visto que esses eram os sujeitos centrais da dinâmica econômica em ascensão nos anos 1930. A extensão destas leis aos trabalhadores rurais se dá somente no ano de 1973, com a 
promulgação da Lei 5889. Desnecessário dizer que o trabalho doméstico não foi incluído no conjunto de leis trabalhistas dos anos 1930, tampouco na regulamentação do trabalho rural dos anos 1970.

Os avanços no estabelecimento de marcos legais para esse tipo de atividade foram graduais: com a Lei 5859 de 1972, garantiu-se a carteira assinada, as férias anuais remuneradas de 20 dias úteis e a contribuição previdenciária. Já com a promulgação da constituição de 1988 foi assegurado o $13^{\circ}$ salário, a exigência de aviso prévio, a licença maternidade, a folga aos domingos e o direito de sindicalização. Ainda que tais garantias tenham se efetivado, percebe-se uma dificuldade evidente na regulamentação do trabalho doméstico - que perpassou todo o século XX e adentrou o século XXI -, visto que este não era considerado trabalho produtivo e, portanto, de baixa importância para o conjunto da economia.

No ano de 2013, no entanto, o Congresso Nacional brasileiro aprovou um conjunto de medidas voltadas à regulamentação do trabalho doméstico, conhecido como a "PEC das domésticas". Dentre os direitos que englobam a Emenda Constitucional n. ${ }^{\circ}$ 72, de 2013 estão: a jornada de trabalho de 44 horas, o seguro desemprego, o salário família, a garantia de hora extra, o adicional noturno, o auxílio creche, o seguro contra acidentes de trabalho, o recolhimento obrigatório do FGTS por parte do empregador, a indenização em demissão sem justa causa, a equiparação das domésticas às demais categorias de trabalhadoras (BRASIL, 2013). Tais medidas se enquadram dentro das recentes 
transformações percebidos no mercado de trabalho brasileiro que, a despeito de apresentarem avanços significativos, também expõem - e em alguns casos potencializam - as inúmeras contradições encravadas na nossa sociedade. É a partir desse contexto que se insere o presente artigo.

O estudo da regulamentação do mercado de trabalho doméstico no Brasil a partir de uma perspectiva crítica é, portanto, de alta relevância para as análises econômicas que buscam interpretações alternativas ao mainstream. $\mathrm{Na}$ medida em que se baseia em óticas interdisciplinares - incorporando tanto questões de gênero quanto a temática do poder $-\mathrm{o}$ presente trabalho foge às abordagens economicistas e dedutivistas próprias do pensamento hegemônico na economia, ou neoclássico. Nesse sentido, ao se propor a estudar uma temática tão atual, partindo da realidade concreta, incorpora-se um elemento normativo voltado à transformação das estruturas sociais e não à mera análise descritiva e pretensamente neutra destas.

Nesse sentido, o presente artigo tem por objetivo a análise do mercado de trabalho doméstico no Brasil, através de um recorte de gênero, com vistas a elucidar tanto os avanços, quanto os desafios que ainda se colocam para as mulheres em um sistema econômico que hierarquiza o trabalho e os trabalhadores em função da contribuição deste para a produtividade do capital. Para tanto, o trabalho está estruturados em três seções, além desta introdução: na seção 2, discutese o recorte de gênero que fundamentam as relações de trabalho, 
sintetizadas na "Divisão Sexual do Trabalho"; posteriormente, na seção 3, são abordados os aspectos do trabalho doméstico no Brasil nos anos 1990 e 2000, tendo sempre como pano de fundo os movimentos macrossistêmicos que orientaram a política econômica dos governos, como o neoliberalismo - no primeiro período - e o crescimento com distribuição de renda - no período mais recente. Finalmente, são traçadas algumas considerações finais sobre os desafios que permeiam o trabalho doméstico no Brasil.

\section{Relações sociais de gênero e o mercado de trabalho}

Para compreender as relações sociais de gênero no âmbito do mercado de trabalho, partimos da constatação de que as sociedades desde as pré-capitalistas - operam segundo uma lógica denominada "Divisão Sexual do Trabalho". Essa forma de divisão do trabalho tem dois sentidos, segundo Kergoat (2003). O primeiro seria o princípio da separação (existem trabalhos de homens e de mulheres) e o segundo princípio seria o da hierarquização (o trabalho dos homens vale mais do que o da mulher). "Esses princípios podem ser aplicados graças a um processo específico de legitimação, a ideologia naturalista, que empurra o gênero para o sexo biológico, reduz as práticas sociais a papéis sociais sexuais, os quais remetem ao destino natural da espécie" (KERGOAT, 2003 p. 56). A divisão sexual do trabalho, portanto, não é neutra no ambiente doméstico familiar (NOGUEIRA, 2006). 
Embora a divisão sexual do trabalho não tenha surgido no interior das sociedades capitalistas, o capitalismo, enquanto um sistema político e ideológico utiliza-se das diferenças sexuais para aprofundar seus processos de inerente de aprofundamento das desigualdades. Nesse sentido, compreendemos que as diferenças de gêneros são responsáveis pela diferenciação de papéis sociais específicos, o que contribuiu para a valoração dos trabalhados desempenhados por homens e mulheres. Com isso, a opressão cultural de gênero, torna-se um expoente da exploração social de gênero, sendo a força de trabalho feminina a mais precarizada e sujeita a menores remunerações. Segundo Hernandez (2009), a divisão do trabalho entre homens e mulheres é parte integrante da divisão social do trabalho.

De um ponto de vista histórico, evidencia-se que as formas atuais da divisão sexual do trabalho cunhadas na exploração do trabalho (Trabalho assalariado/trabalho doméstico; empresa/família) aparece simultaneamente ao capitalismo e um existe em relação ao outro. Nesse sentido, as relações sociais de gênero refletem-se no interior da sociedade capitalista, especialmente nos espaços da família/lar, e na perspectiva do trabalho. Para compreender como a Divisão Sexual do Trabalho se aprofundou ao longo dos anos, faz-se necessário resgatar alguns elementos históricos da inserção da mulher nesse mercado.

Durante a Segunda Guerra Mundial, as mulheres passaram a constituir - de forma significativa - as fileiras desse mercado. Essa entrada massiva de mulheres ocorreu pela necessidade de manutenção 
da força de trabalho global diante de um cenário marcado pela guerra no qual a força de trabalho masculina estava direcionada para essa atividade. Desde esse período as mulheres passaram a ocupar um espaço significativo no mercado de trabalho, embora muitas delas tenham deixados seus postos após 1945.

No entanto, essa entrada numerosa de mulheres no mercado de trabalho foi acompanhada da continuidade dos fatores culturais que caracterizavam a construção social de gênero, e apesar de ocuparem os mesmos postos de trabalho que os homens, as desigualdades seguiram sendo uma característica essencial do mercado de trabalho mundial.

A começar pela caracterização da inserção das mulheres no mercado de trabalho. Primeiramente foi identificado como um elemento conjuntural advinda da necessidade de manter uma produção local, e em segundo lugar, o trabalho das mulheres era visto como um trabalho de complementação de renda, visando contribuir para com a renda do marido ou para suprimento de consumo "supérfluo" das mulheres. Partindo dessa perspectiva era aceitável que a remuneração das mulheres fosse muito inferior a dos homens, uma vez que as tarefas de provimento e sustento das famílias era função dos homens, e "a presença das mulheres no mercado de trabalho era visto como circunstancial e passageira, uma vez que a sua atividade principal era de reprodutora e dona de casa" (TEIXEIRA, 2013, p. 114)

No mercado de trabalho opera uma divisão sexual horizontal de gênero, caracterizada pela concentração em determinados ramos de 
atividade (pelas características culturais atribuídas a identidade feminina). Nesse sentido, as ocupações femininas têm a características comum de estarem ligadas à reprodução social, tarefa que historicamente tem sido desempenhada pelas mulheres. Esse fenômeno que diferencia homens e mulheres por setores econômicos é denominado de "segmentação do mercado de trabalho baseado no gênero".

Além disso, existe uma "Divisão Sexual Vertical de Gênero", que não só divide, mas também hierarquiza o que é trabalho de homens e mulheres, atribuindo determinados valores à sua realização. Nesse sentido, compreende-se que as mulheres estão em uma relação de desvantagens com relações aos homens, no que compreende a remuneração salarial, a ascensão profissional e as condições de trabalho, que são marcadas - prioritariamente - pelo elemento da discriminação e do assédio moral e/ou sexual. O conceito de "pirâmide ocupacional de gênero" retrata bem essa situação, na qual é possível identificar que os trabalho que exigem menos qualificação profissional, que tem menos prestígio social e menos remuneração são ocupados por maioria de mulheres, no entanto os cargos relacionados a chefia, gerência, prestígio social bem como os ligados a participação na esfera pública, são majoritariamente relegados ao sexo masculino. Ainda no que se refere às diferenças/desigualdades no interior do mercado de trabalho, destaca-se a ocorrência de contratação seletiva de mulheres, privilegiando a imagem social, a jovialidade e a não disposição imediata 
de engravidar.

No que tange à experiência profissional as mulheres também largam em desvantagem, isso por que os homens costumam permanecer no mercado de trabalho de forma interrupta - salvo caso de doença - já as mulheres frequentemente ausentam-se no mercado de trabalho por motivos ligados a gravidez, a doenças na família, bem como as situações de recessão econômica e desemprego. "A atividade econômica das mulheres é descontínua, basicamente em razão de momentos cruciais de seu ciclo vital, dos quais o mais relevante é a maternidade" (YANNOULAS, 2002, p. 16)

Por último, destacamos a necessidade histórica naturalizada pelas sociedades de que as tarefas domésticas e de reprodução familiar são de exclusividade feminina. Com isso, as mulheres que adentram no mercado de trabalho precisam conciliar as suas atividades remuneradas com o pleno desempenho das tarefas domésticas, o que caracteriza uma dupla jornada de trabalho.

Entendidos os principais aspectos da divisão sexual (horizontal e vertical) do trabalho, partimos agora para a análise do mercado de trabalho doméstico no Brasil, setor cujos sujeitos centrais são essencialmente mulheres. 


\section{O trabalho doméstico no brasil: caracterizações, problematizações e o período recente}

O sistema de tipo patriarcal, vindo com a colonização portuguesa, imprimiu no Brasil uma imposição imperialista da raça civilizada em contraposição a raça atrasa (FREYRE, 2006). Foi nesse cenário de aculturação nacional em que se instituem os embriões do trabalho doméstico. A estrutura da Casa Grande e da Senzala representava, no seu microcosmo, o sistema político, econômico e social brasileiro, no qual o trabalho era representado pela figura do escravo. O trabalho doméstico das escravas nas Casas Grandes, deixa suas marcas fixadas na história do desenvolvimento do trabalho domésticos - também de tipo remunerado - das trabalhadoras brasileiras. Como na Casa Grande, até hoje temos a presença do sujeito "agregado" (FREYRE, 2006), agora, porém, com dimensões reificadas, mas preservando a herança do trato com as empregadas domésticas em uma esfera pessoal e essencialmente desigual, aparentando, no entanto, apresentar contornos familiares. Segundo Pochamann, "parte significativa das atividades desenvolvidas nos lares brasileiros carrega ainda hoje traços semelhantes observados no passado serviçal e escravista" (POCHMANN, 2012, p. 49).

O trabalho doméstico possui demasiada importância social na produção e reprodução da sociedade, pois é ele que cria, cotidianamente, as condições necessárias para a manutenção da força de 
trabalho, através do provimento do cuidado, da alimentação, da estadia entre outros. Paradoxalmente, no entanto, tanto o trabalho doméstico remunerado quanto o não remunerado, estão na escala dos trabalhos mais desvalorizados socialmente.

As teorias clássicas sobre o trabalho situavam o trabalho reprodutivo no polo oposto ao produtivo. Enquanto este último trata do trabalho que produz riqueza e reproduz o capital, ou daquele que está inserido no mercado de trabalho que gera valor monetário, o trabalho improdutivo é aquele em que "a mão de obra alocada gera valor econômico insuficiente para a sua própria manutenção, o que impede a existência de excedente econômico a ser apropriado por outrem" (POCHMANN, 2012, p. 48). No entanto, só é possível - materialmente - que haja trabalho produtivo na sociedade se existirem sujeitos aptos e com condições objetivas de realizá-lo, o que somente o trabalho reprodutivo é capaz de garantir. A atividade doméstica é invisível para a sociedade capitalista, porém, é fundamental para o desenvolvimento desta, por proporcionar o seu funcionamento, o suporte para a força de trabalho e a reprodução social. (PERROT, 2007).

Considerado tipicamente feminino, o trabalho doméstico historicamente esteve associado à baixa qualificação, a extensas jornadas de trabalho, a baixos salários e a pouca formalização e limitadas garantias trabalhistas. Além disso, existe um importante elemento subjetivo que é marca característica do emprego doméstico. Ele, não raras vezes, não é elevado ao status de trabalho. É comum às 
trabalhadoras domésticas não remuneradas identificarem que "não trabalham" e que "apensas cuidam do lar e da família". Nesse sentido, parece haver um acordo tácito entre empregadores e empregadas de que o trabalho doméstico não necessita passar pela legislação trabalhista vigente. Basta que haja um "acordo" entre as partes, o que na maioria das vezes é feito informalmente. Essa relação com o empregador é marcada por relações interpessoais e familiares, descaracterizando seu caráter profissional.

O trabalho doméstico remunerado assemelha-se a visão de trabalho que historicamente foi sendo construída no imaginário coletivo social do que seja o trabalho das mulheres. A sociedade brasileira tradicionalmente não reconhece o serviço doméstico como um trabalho. Os afazeres do lar, naturalmente relegado às mulheres, dificilmente foram encarados como um trabalho, sendo considerados simples obrigações femininas, sem valor produtivo e econômico, e sem reconhecimento por parte da sociedade. Segundo Pochmann (2012), o trabalho doméstico voltado para as famílias possui características distintas da observada no emprego de mão de obra em outros setores, "sua existência relaciona-se mais à combinação da concentração de renda e riqueza com a existência de parcela significativa de trabalho sobrante às atividades desenvolvidas nos setores públicos e privados" (POCHMANN, 2012, p.46). 


\section{O trabalho doméstico durante o período neoliberal}

A década de 1990, no Brasil, no plano econômico refletiu o movimento internacional de hegemonia do capital financeiro, conhecido como neoliberalismo. O governo de Fernando Henrique Cardoso (1994 - 2002) foi viabilizado e apoiado pelo Fundo Monetário Internacional (FMI), o qual exigiu, em contrapartida, a aplicação de uma política econômica que evitasse a aceleração inflacionária e que, em paralelo, preservasse a recente abertura comercial e financeira (BALTAR et alli, 2009). Nesse sentido, os pilares de sustentação do Plano Real basearamse no tripé: metas de inflação, superávit primário e taxa de câmbio flutuante. Tal conjugação, a despeito de lograr avanços no que diz respeito à estabilidade inflacionária, provocou a sujeição da política econômica a fatores externos, vulnerabilizando o Estado e a sociedade brasileira frente à primazia das finanças.

A política de câmbio flutuante expressou a continuidade da política cambial: o país continuou renunciando ao poder de usar a taxa de câmbio como instrumento para orientar o desenvolvimento e para exportar mais produtos manufaturados e depender menos de importações desses produtos (BALTAR et alli, 2009, p. 4).

Em síntese, a aplicação da política neoliberal no Brasil, a partir dos anos 90, respondeu mais aos interesses do capital internacional, perseguindo investimentos mais lucrativos, do que ao processo de 
crescimento interno. Como resultado, assistiu-se uma reestruturação produtiva, calcada em um baixo dinamismo econômico e, no que tange ao mercado de trabalho, vivenciou-se um período de taxas de desemprego elevadas, de flexibilização das relações trabalhistas e de escassos ganhos salariais.

Nesse cenário de estagnação e recessão econômica, com a emergência de medidas que visavam precarizar e flexibilizar o trabalho no Brasil, os trabalhadores menos qualificados - e em especial as mulheres - identificavam no trabalho doméstico uma alternativa para a obtenção de uma remuneração que, apesar de baixa, garantia seu provimento e de suas famílias. Dessa forma, durante os anos 90, o trabalho doméstico permaneceu como o $2^{\circ}$ e $1^{\circ}$ tipos de serviço na ocupação de mão de obra feminina, como mostram os dados da PNAD (2009). 


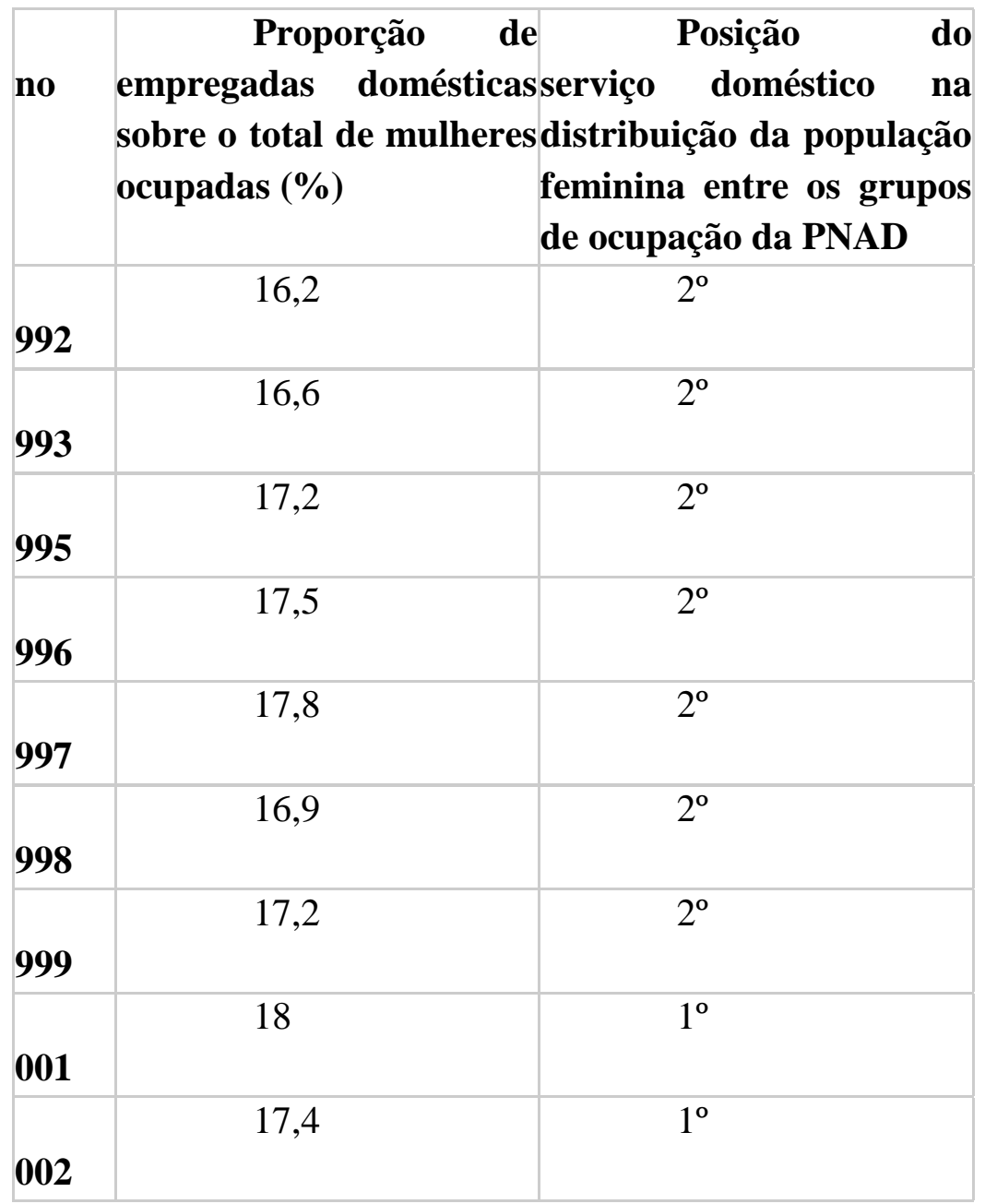

Fonte: PNAD. Elaboração própria.

Analisando esses dados, verifica-se que o trabalho doméstico constitui um elemento que oscila conforme se modificam as condições sociais e econômicas no Brasil, apresentando cifras mais elevadas - em 
termos proporcionais e absolutos - durante o período de liberalização econômica vivenciado no período do governo FHC.

\section{O trabalho doméstico na era Lula-Dilma}

A partir de 2002, com a eleição de Luis Inácio Lula da Silva, uma série de transformações entram em curso na economia brasileira, sendo que, a principal delas diz respeito à maior participação do Estado na orientação da economia. Diferentemente do período neoliberal - em que se observou a sujeição do Estado brasileiro aos interesses do capital financeiro internacional - os anos que se seguiram à eleição de Lula, demonstram uma postura mais assertiva do Estado tanto na regulamentação de mercados (financeiro, de trabalho, etc.), quanto na elaboração de políticas públicas voltadas para a diminuição das desigualdades de renda. Vale destacar, no entanto, que, sendo o neoliberalismo um processo de acumulação sistêmico, este não foi combatido em sua plenitude, mas apenas foram minorados os seus efeitos em um conjunto de setores da economia brasileira.

No que diz respeito ao mercado de trabalho, por exemplo, são perceptíveis as transformações positivas observadas no período especialmente no segundo mandato, do governo Lula - materializadas, dentre outras, por uma melhora significativa da renda do trabalho decorrente da política de valorização do salário mínimo. Em que pesa a ocorrência de uma crise financeira internacional, 483 mil trabalhadores 
foram formalizados, o que representa uma alta de 1,5\% em relação a 2008 (PNAD2011). Ainda na mesma pesquisa verifica-se que 53,5\% dos trabalhadores em 2011 contribuíram para a previdência social. Cinco anos antes, essa proporção era de apenas 46,4\%

No que tange ao trabalho doméstico, a análise dos dados da PNAD de 2004 e 2011 mostra que este tem deixado de ser a principal atividade na qual estão inseridas as trabalhadoras. Da mesma forma, observa-se que esse tipo de atividade tem perdido seu peso proporcional e absoluto - no mercado de trabalho. Isso pode ser explicado pela melhora no mercado de trabalho vivenciado nos anos 2000, bem como as melhoras nas condições de acesso ao ensino superior e o aumento na perspectiva econômica de vida dos trabalhadores, em especial das mulheres.

Em 2001, 18\% da mão de obra feminina estava ocupada no trabalho doméstico, e em 2011 esse percentual caiu para 15,6\%. Além disso, o trabalho doméstico caiu de $1^{\circ}$ lugar na absorção do trabalho feminino em 2001 e 2002 para $3^{\circ}$ em 2011 (PNAD 2011). Ressalta-se, ainda, o fato de que o número de trabalhadoras dessa categoria que obteve carteira de trabalho assinada aumentou 12,4\% em 2011. Entre 2004 e 2009 houve um aumento de 11,9\% no contingente de trabalho doméstico. 
Gráfico 3.16- Evolução da composição do trabalho doméstico entre com e sem carteira assinada entre 1995 e 2012.

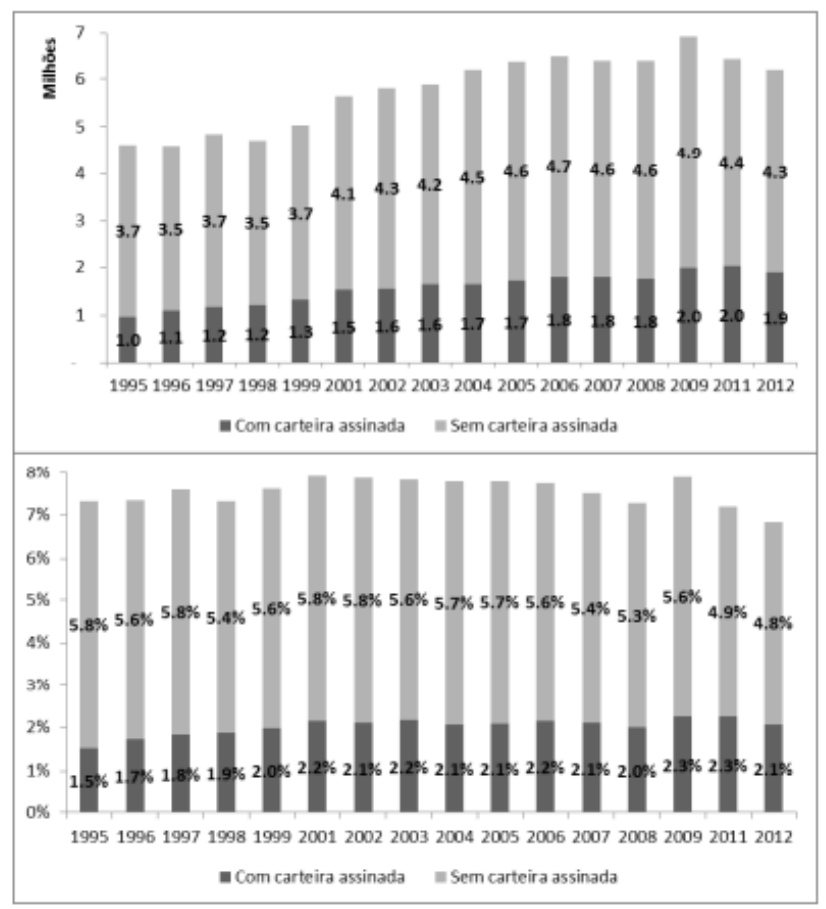

Fonte: Rodrigues e Ramos, 2013

Esse gráfico permite constatar que o trabalho doméstico tem apresentado uma trajetória de redução nos últimos anos da década de 2000. No entanto, vale destacar que cerca de $70 \%$ da mão de obra feminina ocupada no trabalho doméstico ainda se encontra na informalidade (RODRIGUES; RAMOS, 2013). Além disso, apesar da diminuição do contingente das trabalhadoras no trabalho doméstico, este permanece relativamente estável nesses últimos 20 anos, oscilando 
entre a $1^{\mathrm{a}}$ e a $3^{\mathrm{a}}$ posição na absorção de mão de obra geral feminina.

\section{Considerações finais}

O presente artigo buscou apresentar, a partir de um recorte de gênero, algumas características presentes no mercado de trabalho doméstico do Brasil, atentando para algumas transformações pela qual este passou nos anos recentes - sendo a publicação da Emenda Constitucional 72/2013, ou "PEC das Domésticas" o elemento central dessas mudanças. Abaixo, tecemos as principais conclusões deste estudo e esboçamos alguns questionamentos e desafios a serem enfrentados no que diz respeito à regulamentação do trabalho doméstico no Brasil.

Em primeiro lugar, sabemos que o mercado de trabalho no Brasil, apesar dos recentes avanços, reflete ainda um aspecto remanescente da sua história colonial: a manutenção da divisão sexual do trabalho que hierarquiza e classifica a classe trabalhadora de acordo com o sexo. Dessa lógica, surge um recorte claro entre trabalhos predominantemente masculinos $\mathrm{e}$ trabalhos predominantemente femininos. Para além da divisão, tal herança incute a essas duas categorias um juízo de valor, ou seja: trabalhos predominantemente masculinos não somente são dirigidos aos homens, como também são mais valorizados e reconhecidos, visto que são capazes de contribuir de maneira mais eficiente para a produtividade geral da economia; de 
modo contrário, os trabalhos predominantemente femininos, por serem reprodutivos e não produtivos, contribuem menos para a geração de riquezas e para a acumulação e, por isso, são menos valorizados. O mercado de trabalho doméstico deixa essa divisão sexual do trabalho mais evidente.

Em segundo lugar, ainda que, conforme apresentado ao longo do texto, alguns avanços puderam ser observados nos anos recentes como a diminuição do trabalho feminino doméstico nos anos 2000 e o aumento da formalização do mesmo - a regulamentação do trabalho doméstico de maneira mais efetiva, bem como o rompimento com o preconceito que o circunda são tarefas inacabadas que exigem um alto grau de comprometimento tanto por parte do governo brasileiro quanto por parte da sociedade civil (incluindo nessa, em especial, os grupos de pressão e sindicatos das trabalhadoras domésticas).

Nesse sentido há muito ainda no que avançar. O trabalho doméstico é um ramo da atividade econômica bastante difundido no Brasil (em especial, entre os estratos da alta classe média que possuem renda suficiente para contratar o serviço doméstico), e que apresenta uma profunda herança cultural, aliada a uma enorme concentração de renda. É preciso enfrentar essa herança escravocrata e servil, regulamentando essa profissão como trabalho, e retirando-o da dimensão pessoal, afetiva e familiar que lhe tem conferido o status de um não-trabalho, mas de uma extensão das tarefas "naturais" atribuídas culturalmente as mulheres. 


\section{Referências}

BALTAR, P.; SANTOS, A.; GARRIDO, F. \& PRONI, M. Estrutura do emprego e da renda. In:LAPLANE, M. \& HIRATUKA, C. (orgs.) Perspectivas do Investimento no Brasil. Rio de Janeiro:BNDES; Campinas: IE-Unicamp, 2009.

BRASIL. Emenda Constitucional $n^{o}$ 72, de 2 de abril de 2013. Disponível em: < http://portal.mte.gov.br/trab_domestico/emendaconstitucional-n-72/>

FREYRE, Gilberto. Casa-grande \& Senzala: formação da família brasileira sob o regime da economia patriarcal. 51 a Ed. São Paulo: Global, 2006.

HARNANDEZ, Carmem Osório. Política de crédito Rural com Perspectiva de gênero: um meio de empoderamento para as mulheres rurais?. UFRGS, Porto Alegre, 2009

KERGOAT, Daniéle. Divisão sexual do trabalho e relações sociais de sexo. In: Trabalho e cidadania ativa para as mulheres. Prefeitura Municipal de São Paulo: Coordenadoria especial da mulher. São Paulo, 2003 
NOGUEIRA, Claudia Mazzei. O trabalho Duplicado: a divisão sexual do trabalho e na reprodução: um estudo das trabalhadoras de telemarketing. São Paulo: Expressão Popular, 2006.

PERROT, Michelle. Minha História das Mulheres. São Paulo: Contexto, 2007.

POCHMANN, Marcio. Sobre a Nova Condição de Agregado Social no Brasil: algumas considerações. Revista Paranaense de Desenvolvimento. Curitiba, n. 105. Jul/dez 2003.

. Nova classe média? O trabalho na base da pirâmide social brasileira. Boitempo editorial, São Paulo, 2012

RODRIGUES, Flora Toledo; RAMOS, Carlos Alberto. Pleno emprego no Brasil: considerações teóricas e análise empírica. Universidade de Brasília, Brasília, 2013

TEIXEIRA, Marilane Oliveria. O mercado de trabalho reitera relações desiguais que se constroem no âmbito das relações econômica e sociais. In: Classes, que classes? ciclo de debates sobre classes sociais. Perseu Abramo, São Paulo, 2013

YANNOULAS, Silvia Cristina. Dossiê: políticas públicas e relações de gênero no mercado de trabalho. Brasilia: CFEMEA; FIG/CIDA, 2002. 